
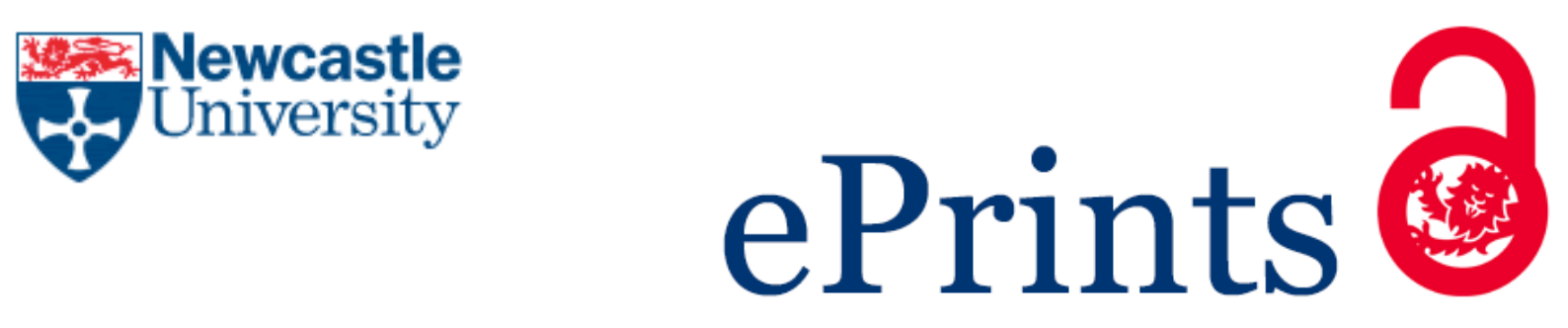

Sarhosis V, Lavis S, Mostade M, Thomas HR. Towards commercialising underground coal gasification in the EU. Environmental Geotechnics 2016. DOI: 10.1680/jenge.15.00044

\title{
Copyright:
}

Copyright @ ICE Publishing 2016, all rights reserved. Published in Environmental Geotechnics http://www.icevirtuallibrary.com/toc/jenge/current

DOI link to article:

http://dx.doi.org/10.1680/ienge.15.00044

Date deposited:

$09 / 06 / 2016$

Embargo release date:

08 April 2017 


\section{Towards commercialising underground coal gasification in the EU}

1 Vasilis Sarhosis PhD, MSc, BSC Lecturer, School of Civil Engineering and Geosciences, Newcastle University, Newcastle upon Tyne, UK Geoenvironmental Research Centre, Cardiff School of Engineering, Cardiff University, Cardiff, UK (corresponding author: vasilis.sarhosis@newcastle.ac.uk)

2. Shaun Lavis PhD, MSc, BSc Most Coal Engineering, Liège, Belgium
3 Marc Mostade MSc Director, Most Coal Engineering, Liège, Belgium

4 Hywel R. Thomas PhD, MSc, BEng

Director, Geoenvironmental Research Centre, Cardiff School of Engineering, Cardiff University, Cardiff, UK
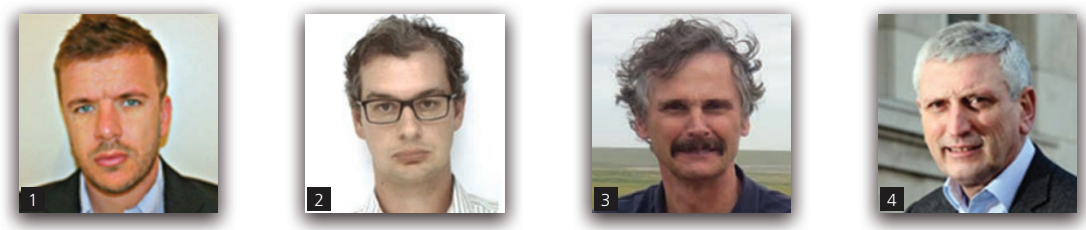

Modern 'enabling technologies' and over a century of research and development have pushed underground coal gasification (UCG) beyond the proof-of-concept phase. Lessons learned from previous trials have demonstrated that UCG can exploit the energy stored in coal efficiently and with limited environmental impact compared with conventional coal-based energy technologies. Many countries in the EU (and worldwide) struggle to meet their energy needs despite containing very large reserves of coal, which cannot be exploited conventionally because of its depth. Application of modern UCG techniques, state-of-the-art drilling and monitoring technologies offer the opportunity to extract the energy from deep coal resources economically and with limited environmental impacts; however, several hurdles, such as public opinion and carbon dioxide $\left(\mathrm{CO}_{2}\right)$ emission limits, must be overcome before UCG can be commercialised in the EU. Continued support by member states will attract more private investments, enable more field trials and allow Europe's world-class UCG experts to demonstrate that the technology is ready to provide cleaner energy from coal for the EU in the twenty-first century. This is a review paper that aims to summarise the lessons learned from UCG trials and EU-sponsored work and to discuss what still needs to be done to commercialise UCG.

\section{Introduction}

Despite the current drive to reduce pollutant and carbon dioxide $\left(\mathrm{CO}_{2}\right)$ emissions from fossil fuels, coal and other fossil fuels will continue to be a major source of energy in the future. According to the International Energy Agency (IEA, 2014), the global demand for coal will increase on average by $2 \cdot 1 \%$ per year through 2019 , being mainly driven by emerging economies. Despite the increasing contribution of renewable energy sources, it is difficult to see how targets for emission reduction from fossil fuels can be achieved by using current conventional coal-based technologies. The key to balance the tension between increasing coal use and the requirements for reduced pollutant (e.g. particulates, nitrogen oxides $\left(\mathrm{NO}_{x}\right)$ and sulfur oxides $\left(\mathrm{SO}_{x}\right)$ ) and carbon dioxide emissions is the use of clean coal technologies. One such technology is underground coal gasification (UCG), which has the potential to contribute to the future energy needs of coal-bearing countries in the EU (and worldwide) in a cleaner and safer way (Bhutto et al., 2013; Creedy et al., 2001; Friedmann et al., 2009; Sheng et al., 2015; Stanczyk et al., 2011).

UCG is the same chemical process used commercially by surface gasification plants to convert solid coal into a mixture of mostly combustible gases (e.g. methane $\left(\mathrm{CH}_{4}\right)$, carbon monoxide $(\mathrm{CO})$ and hydrogen $\left(\mathrm{H}_{2}\right)$ ) known as synthesis gas or 'syngas'. Unlike surface gasification, UCG is undertaken on site in deep, carefully selected coal seams that are otherwise unmineable (Figure 1). The coal is gasified by injecting oxidants through a borehole (the injection well) into the coal seam and partially combusting the coal. The syngas flows at a very low velocity and under pressure to a second borehole (the production well) and to the surface, leaving almost all of the coal ash behind. The combination of linked injection and production wells is known as a 'module'. Once at the surface, conventional technologies are used to remove 


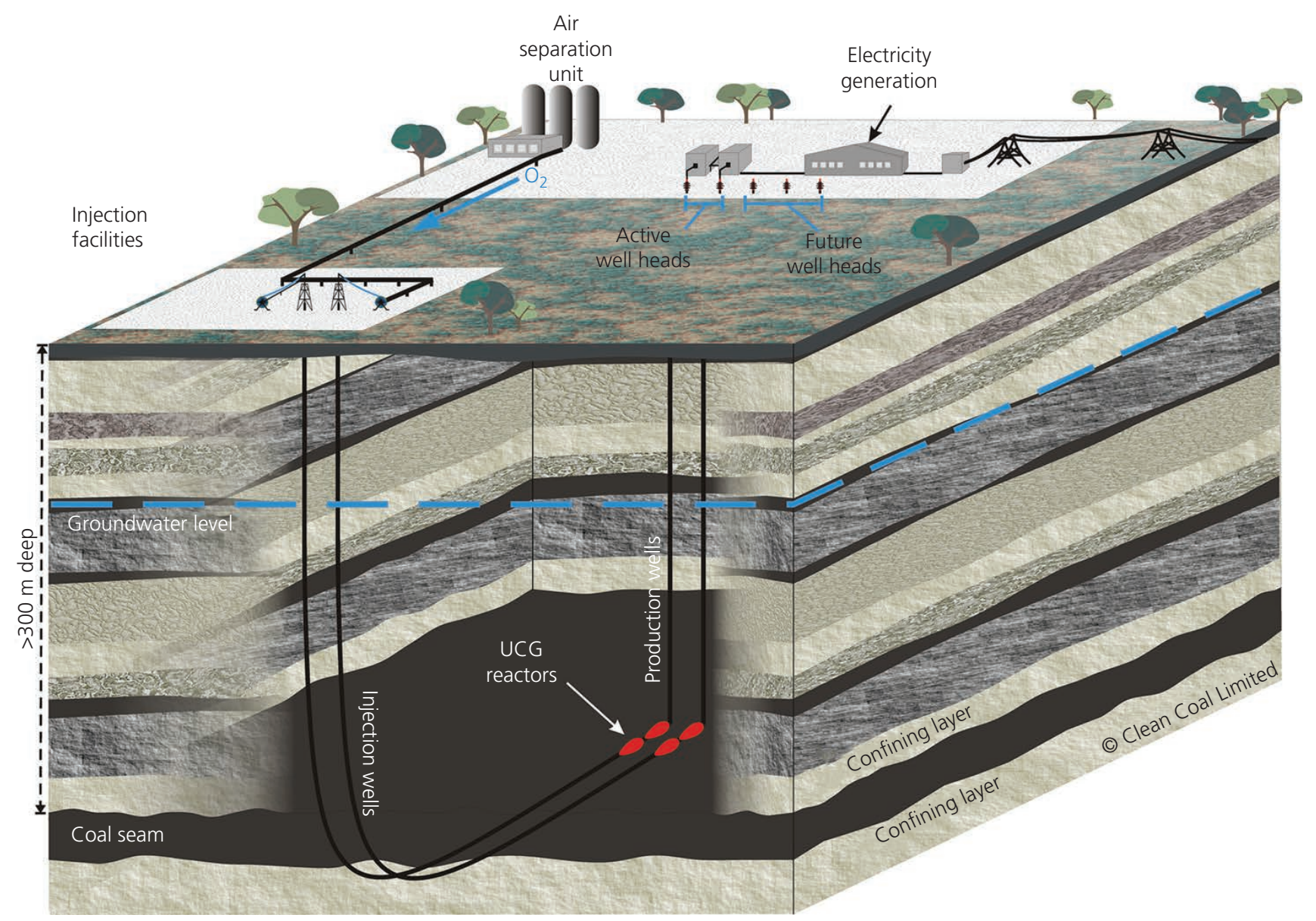

Figure 1. A UCG module and possible surface plant (not to scale) (Courtesy of Clean Coal Limited)

the remaining pollutants and to generate electricity or manufacture liquid fuels and industrial chemicals from the syngas.

Compared with conventional coal-based energy technologies, UCG has a significantly lower environmental impact because coal is not mined, transported or processed and because it generates significantly smaller volumes of waste products (e.g. fly ash) and pollutants. Coupled with existing technologies for carbon dioxide capture, UCG has the potential to recover energy from coal with reduced carbon dioxide (Kempka et al., 2011; Roddy and Younger, 2010; Sarhosis et al., 2013).

Despite its potential, and over a century of development, UCG has never been commercialised. Now, however, the results of several field trials and new enabling technologies (e.g. directional drilling) have pushed UCG beyond the 'proof-of-concept' phase and into the commercialisation phase. This is a review paper that aims to summarise the lessons learned from UCG trials and EUsponsored work and to discuss what still needs to be done to commercialise UCG.

\section{Demand for UCG in the EU}

Many EU member states are heavily reliant on a single supplier of primary energy, including six who are entirely dependent on natural gas imports. In response to the winter gas shortages in 2006 and 2009 and recent geopolitical issues, the need for diversified, resilient, low-carbon dioxide domestic energy sources is of extreme importance for Europe. Efforts to develop renewable resources have met considerable success, but fossil fuel usage is expected to account for up to $66 \%$ of primary energy consumption until at least 2035 (BP, 2015).

At the same time as indigenous energy supplies become ever more important, the EU's fossil fuel resources, particularly oil and gas, are declining and gas imports are set to increase significantly (BP, 2015). Europe's coal resources remain large, but underground coal mining becomes more difficult, dangerous and expensive as the shallow, easily mined coal is progressively consumed; mining below $500 \mathrm{~m}$ is generally not economic, yet $80 \%$ of Europe's coal resources lie below this depth (Euracoal, 2013). These resources could be recovered economically by UCG, which is uniquely 
suited to exploiting deep unmineable coal with reduced environmental impacts compared with conventional technologies.

Data on coal resources suitable for UCG in Europe are limited, but a conservative estimate by the British Geological Survey indicates that the UK alone has about $16.7 \mathrm{Bt}$ of coal suitable for UCG, which, according to UCGP (2007), equates to about 1700 billion $\mathrm{m}^{3}$ natural gas or 17 years of extra gas reserves. For similar coal-rich/gas-poor countries, such as Poland and other Eastern European countries, UCG could offer an important opportunity to become less reliant on gas imports.

\section{Lessons learned on the path to commercialisation}

There have been a total of around 50 UCG trials undertaken in the former USSR, the USA, Canada, Europe, China, South Africa, New Zealand and Australia. Despite most of the trials being short lived, except for the Yerostigaz project in Angren, Uzbekistan (which has been operating for over 50 years), more than $15 \mathrm{Mt}$ of coal has been gasified on site (Younger, 2011). The trials showed that UCG is highly adaptive to different conditions; it has been undertaken in horizontal seams and steeply dipping seams (i.e. coal seams that have been reorientated from horizontal to angles over $60^{\circ}$ ), as well as in coals of different rank and at different depths, from $<50$ to $1500 \mathrm{~m}$ deep.

The trials also demonstrated that UCG is a highly efficient coalconversion process, with gasification efficiencies (i.e. the ratio of the energy in the coal gasified to that in the produced syngas) of $75-85 \%$, which is similar to that of surface gasifiers (Cena et al., 1988), and mining efficiencies (i.e. the ratio of the mass of coal removed by gasification to the mass of coal originally in place) at around $60 \%$, which is comparable with that of underground coal mining. Although not all of the trials were successful, and some early trials unfortunately caused environmental damage (e.g. the US Hoe Creek trials in 1970s), they provided the lessons necessary to move UCG beyond the proof-of-concept phase. The key lessons are the following.

(a) Choose the most efficient UCG module design.

(b) Operate and monitor the facility according to strict guidelines.

(c) Manage geoenvironmental risks.

(d) Choose the correct site.

(e) Commercialise progressively.

\section{UCG modules}

All UCG modules require a minimum of an injection well to inject the oxidising agents and start ignition and a production well to recover the syngas. There are currently three types of module configuration: the linked vertical well (LVW); the controlled retracting injection point (CRIP) and the steeply dipping bed (SDB) (Figure 2).

LVW is the oldest of the three configurations and was developed during a major phase of experimentation in the former USSR.
Variants of the LVW method are still used today, most notably at the Angren facility in Uzbekistan. The LVWs can be linked by enhancing the natural permeability of the coal seam, by using techniques such as 'reverse-combustion' (Blindermann et al., 2008), electrolinking or hydrofracking (Couch, 2009) or by using a third directionally drilled borehole to link the wells. The last technique was first tested during a US trial known as Rocky Mountain 1 (RM-1) and is thought to have been used in the early phases of some Chinese, Australian and South African projects.

The CRIP method was first used in the 1980s by the USA and was developed further during trials in Spain (1990s), Australia (late 1990s to the present) and recently in Alberta, Canada. Two different CRIP configurations have been developed: the linear CRIP (L-CRIP) and the parallel CRIP (P-CRIP). In the L-CRIP configuration, the injection well is drilled along the base of the coal seam to intersect the production well and gasification proceeds along the in-seam section of the injection well. This technique was most recently used at the 1500 m-deep UCG trial at Swan Hills, Alberta, Canada (Swan Hills Synfuels, 2012).

In the P-CRIP configuration, both process wells are drilled parallel to each other within the coal seam. Once the in-seam sections have reached a predetermined length, the two process wells are deviated towards the base of a third borehole drilled vertically into the coal seam. The third well is used to ignite the coal at the start of operations. This technique was first tested during the 'Tono 1' trial in the USA and again in the RM-1 trial, where it was compared directly with an LVW module (Cena et al., 1988).

The SDB configuration was used for gasifying coal in SDBs during early trials in Russia and Europe and was developed further in the USA at trials in Rawlins, Wyoming, during the 1980s, with some considerable success (Burton et al., 2006; Couch, 2009).

While LVW modules are relatively inexpensive to build (the directional drilling required by CRIP modules is expensive), there are several reasons why this technology is falling out of favour. Previous trials, particularly the RM-1 trial, showed that CRIP modules gasify coal more efficiently than LVWs (Cena et al., 1988) and that LVW suffer from the 'overriding effect', where gasification occurs progressively higher in the coal seam until it occurs only across the top, leaving the coal beneath unaffected. Furthermore, LVW modules depend on enhancing natural permeability to link the wells, but as natural permeability decreases with increasing depth, there comes a point at which it is not possible to complete the link between process points. These factors, together with the current trend towards deeper gasification (Younger, 2011), have resulted in CRIP configurations being increasingly favoured in recent attempts to commercialise UCG.

\section{Operating and monitoring UCG reactors}

The correct operation of UCG modules is essential for protecting the environment and ensuring efficient gasification. Three factors 


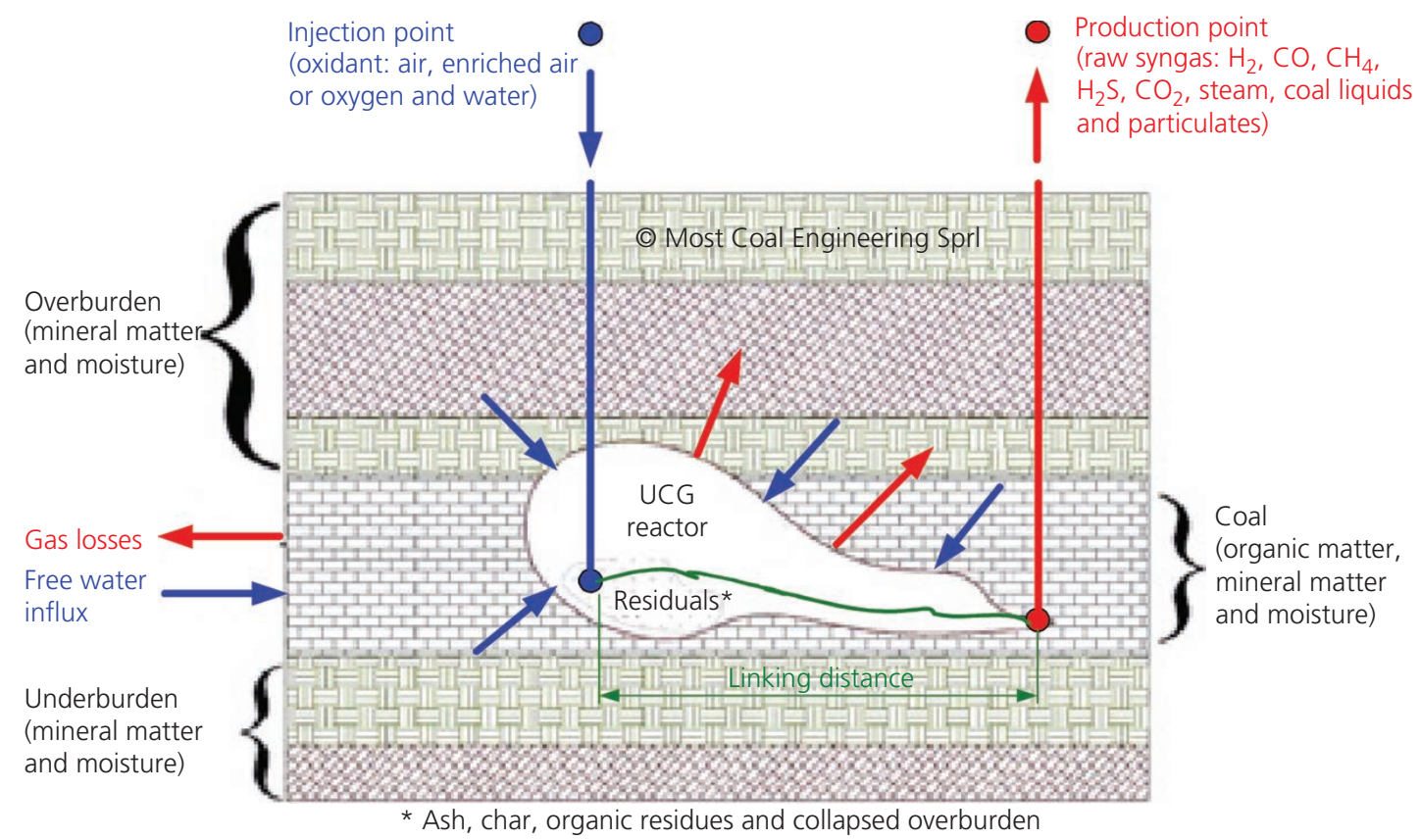

(a)

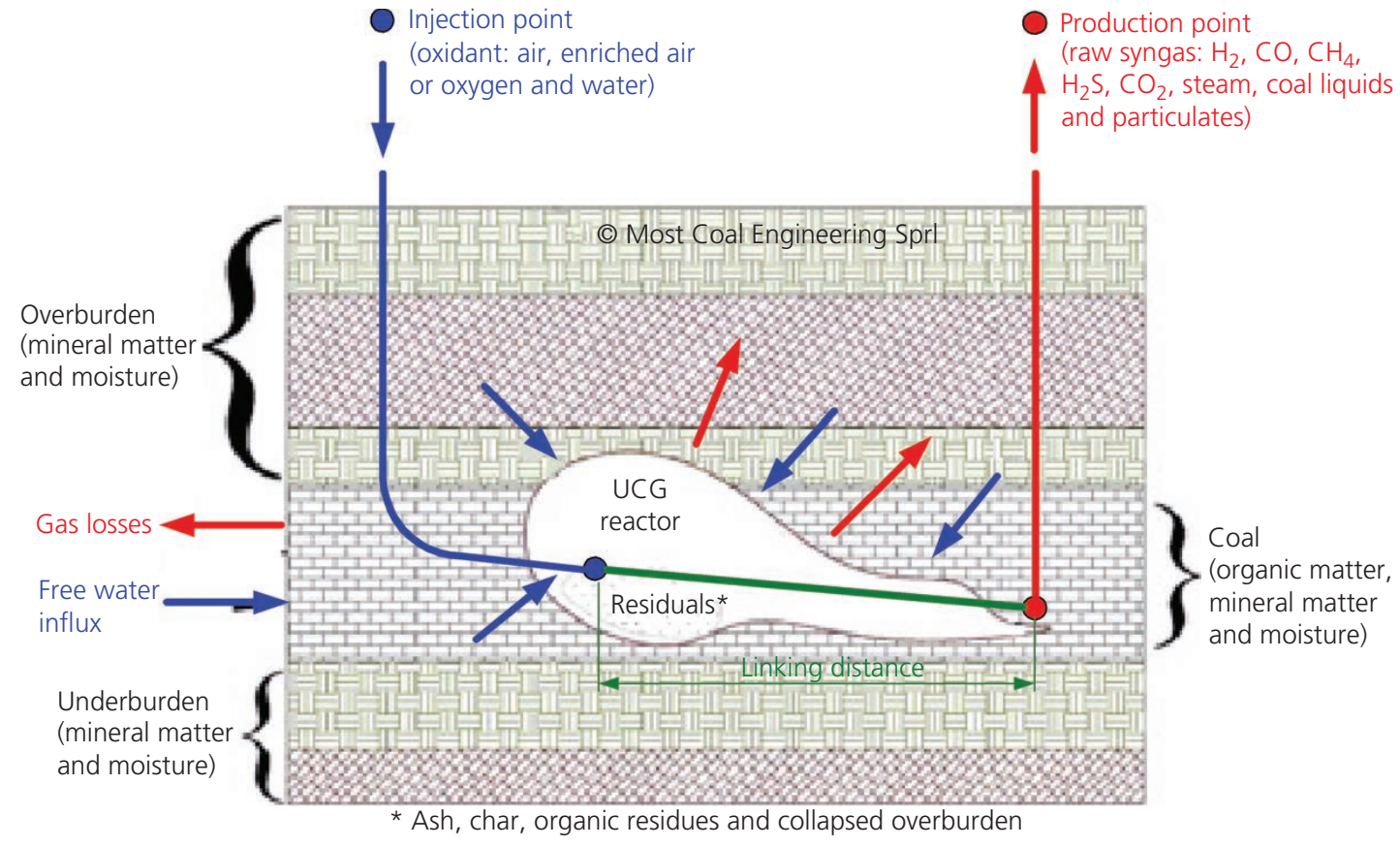

(b)

Figure 2. Module configurations for UCG development: (a) LWW;

(b) CRIP - linear; (c) SDB (continued on next page)

are critical: $(a)$ the pressure of the reactor compared with that of the surroundings, (b) gasification efficiency and (c) reactor decommissioning.

\section{Operating and monitoring UCG reactors}

When a UCG reactor is operated properly, its pressure depends on the rate of oxidant and water injection and the rate at which the syngas can exit the production well. If the pressure becomes too high, however, a third factor becomes important: gas loss by way of leakage through the reactor walls. To avoid this, UCG should take place in low-permeability coal and rocks that are water saturated. Water in the pore spaces of the rock seals the reactor and ensures that the reactor remains a 'closed system'. The closed system will be maintained only if the reactor pressure is less than 


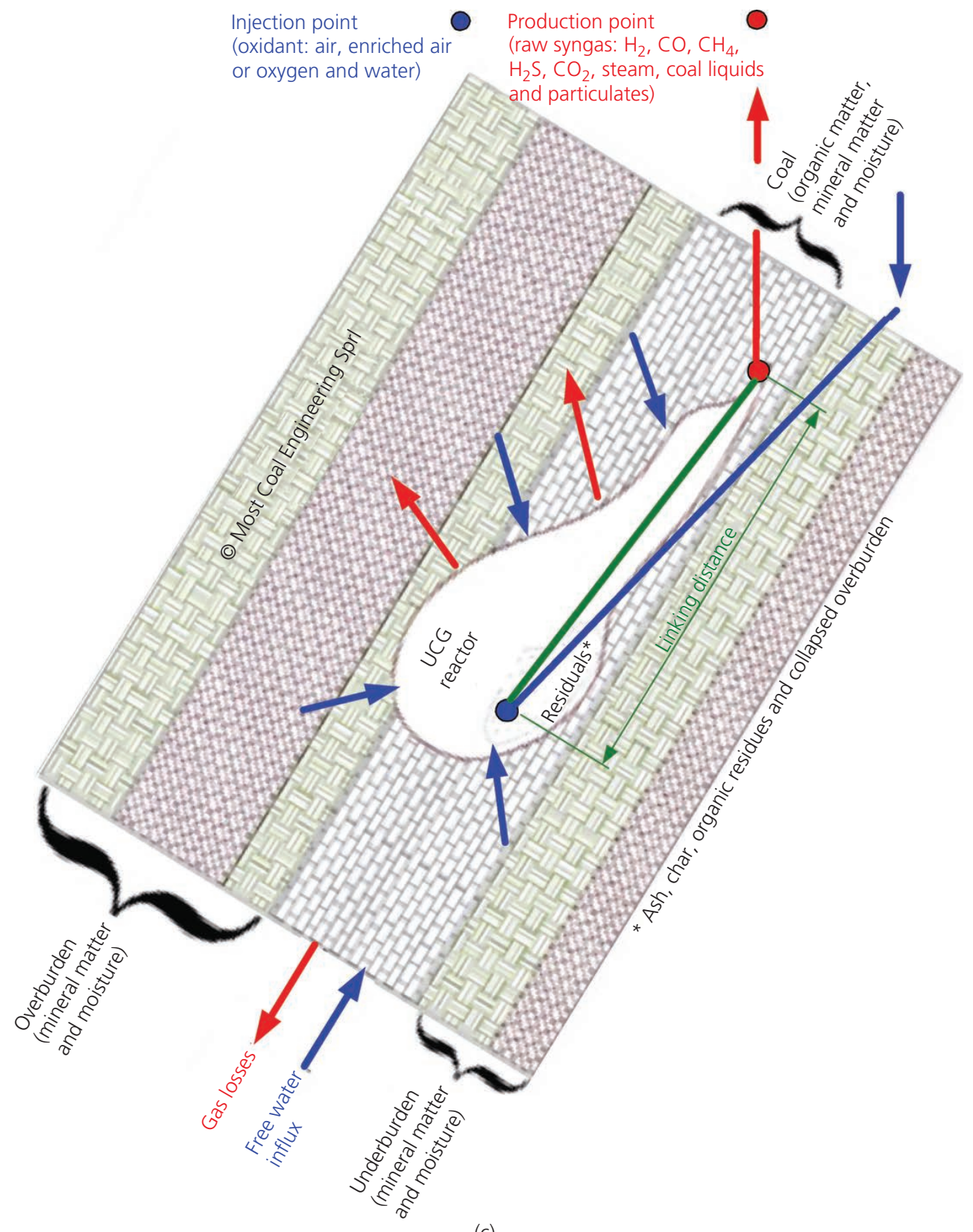

(c)

Figure 2. Continued

the porewater/groundwater pressure (or hydrostatic pressure). If the reactor pressure exceeds the hydrostatic pressure, syngas will be forced through the pore spaces in the rock/coal surrounding the reactor, displacing the porewater and escaping into the surroundings (Figure 3). UCG operators now continuously monitor reactor pressures to ensure that they never exceed hydrostatic pressure.

\section{Gasification efficiency}

During UCG, gasification and pyrolysis occur simultaneously. Gasification occurs at higher temperatures and produces lowmolecular-weight gases that are removed efficiently from the
UCG reactor. In contrast, pyrolysis occurs at lower temperatures and produces high-molecular-weight compounds, some of which readily condense in the subsurface, are potentially contaminative and are difficult to remove from the system. It is therefore necessary to maximise gasification over pyrolysis by minimising the amount of heat lost from the system - that is, maximising the gasification efficiency. This is achieved by using the most efficient UCG module configuration and by choosing the most efficient oxidant and oxidant injection rate (Cena et al., 1988; Konstantinou and Marsh, 2015; Osborne, 2013). As is generally the case for surface gasification, pure oxygen is used instead of 


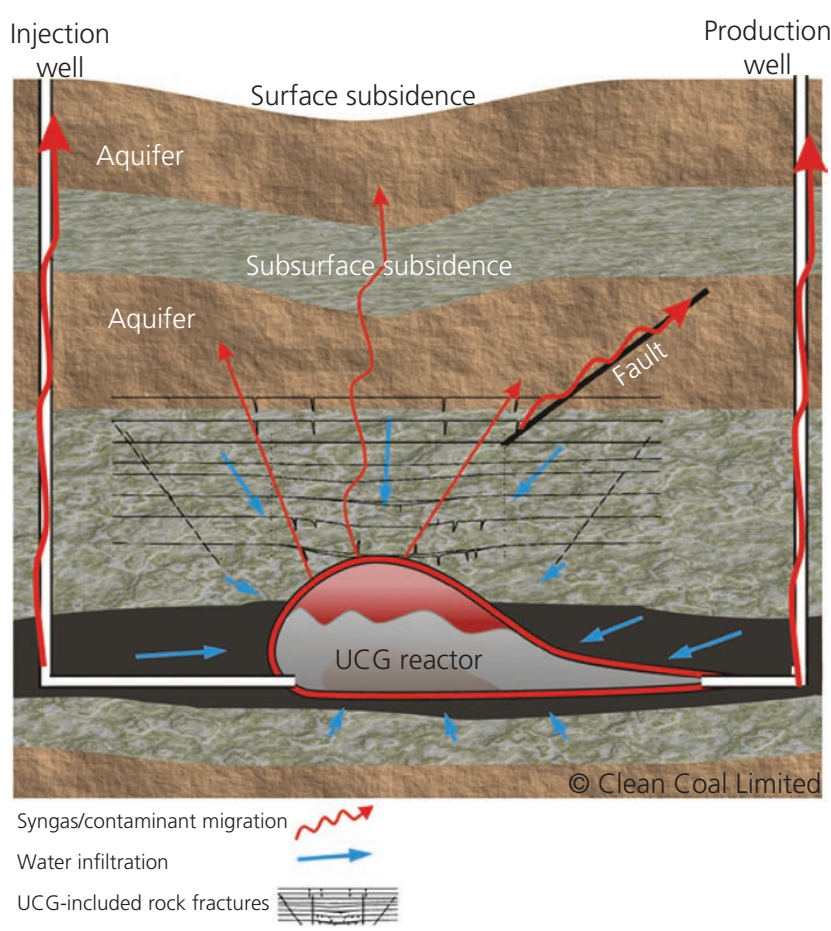

Figure 3. Potential pathways for pollutant migration

air (or enriched air) in modern UCG because it improves gasification efficiency ( $>20 \%$ increase) and reduces the volumes of gases flowing through the module, which lowers the cost of building UCG modules because smaller-diameter boreholes and completion equipment are required. The use of pure oxygen also increases the calorific value of the syngas from lower than $4 \mathrm{MJ} / \mathrm{N} \mathrm{m}^{3}$ with air to $>12 \mathrm{MJ} / \mathrm{N} \mathrm{m}^{3}$ with pure oxygen.

\section{Decommissioning}

UCG operators have to carefully decommission UCG modules after use because the reactors can remain very hot for time periods on the order of years (Sarhosis et al., 2013). Left unmanaged, high reactor temperatures can allow coal to continue to pyrolyse and water to vaporise, which could raise the reactor pressure above the hydrostatic pressure and elevate the risk of environmental impact. To prevent this, the 'clean cavern' technique was developed (Boysen et al., 1990), which involves quenching the reactor with water and nitrogen to stop coal pyrolysis quickly. The reactor is allowed to vent continuously during quenching to avoid the pressure exceeding hydrostatic pressure. The water recovered at the surface is processed to recover pyrolysis products.

\section{Managing geoenvironmental risks}

Some previous trials, particularly the US Hoe Creek trials undertaken in the 1970s, caused groundwater contamination and subsidence. Although the ground used by the Hoe Creek trials has since been remediated, the unfortunate incidents have enabled the environmental risks of UCG to be understood and riskmanagement strategies to be developed.
Disregarding the reactor pressure (for discussion, see the 'Decommissioning' section), the risks of pollutant migration out of the georeactor and of surface subsidence are associated closely with the development of the subsurface cavity (i.e. the georeactor). As coal is progressively gasified, the overlying strata becomes unsupported (in essentially the same way as with coal mining, although the surrounding strata remain water saturated during UCG), causing the loss of support to the overburden and a build-up of stress. The exact geomechanical response of overburden to the development of a UCG cavity is highly complex and strongly influenced by site-specific conditions (e.g. the thickness and strength of overlying rock layers, dip angles and the existence of faults). Nevertheless, Younger (2011) discusses generic geomechanical responses to UCG that could be expected above a UCG reactor in horizontal strata: initially, the UCG reactor will collapse and be filled by brecciated roof rocks (or 'goaf'). Above the breccia-filled cavity, an inverted cone-shaped zone of deformation develops that is defined by an 'angle of draw' (Figure 4). Rocks immediately above the cavity (extending for about one third the width of the UCG cavity) undergo extensional deformation and crack and sag as a result. Above this initial extensional zone, rock layers become compressed, in a 'pressure arch', above which a second zone of net extension extends towards the surface. Rock permeability within the zones of net extension becomes enhanced, and those in the pressure arch become diminished and can act to isolate further any overlying aquifers from the georeactor. This simplified picture, however, is complicated if pre-existing fault surfaces exist within the zone of deformation.

As it is not feasible to build structures to support the overburden during UCG, risk management strategies are focused on choosing a site with the appropriate geology. The key is to minimise the development of preferential pathways to sensitive 'receptors' (i.e. shallow potable aquifers and the surface) by choosing deep coal seams (i.e. $>300 \mathrm{~m}$ deep) that are overlain by thick, strong, lowpermeability layers (such as siltstones and mudstones) with minimal fractures.

The deeper the coal seam, the less the probability of surface subsidence (Mastalerz et al., 2011; Yang et al., 2014) and a minimum of $15 \mathrm{~m}$ of consolidated rock above the coal seam is recommended (Mastalerz et al., 2011). The closer UCG is undertaken to a fault, the higher the risk of fault reactivation and gas leakage (Burton et al., 2006; Sury et al., 2004), and according to DTI (2004), a minimum distance of $0.8 \mathrm{~km}$ from major fault zones should be adopted. The acceptable distance between a UCG site and a fault zone, however, should be determined on a site-bysite basis (Sheng et al., 2015).

Relatively impermeable rock around the coal seam helps to prevent the escape of product gases, as well as reduce the flow of groundwater into the seam. Gases and pyrolysis contaminants in and around the gasification cavity should be 'contained' by groundwater if pressures within the gasification reactor are less than or equal to hydrostatic pressure. 


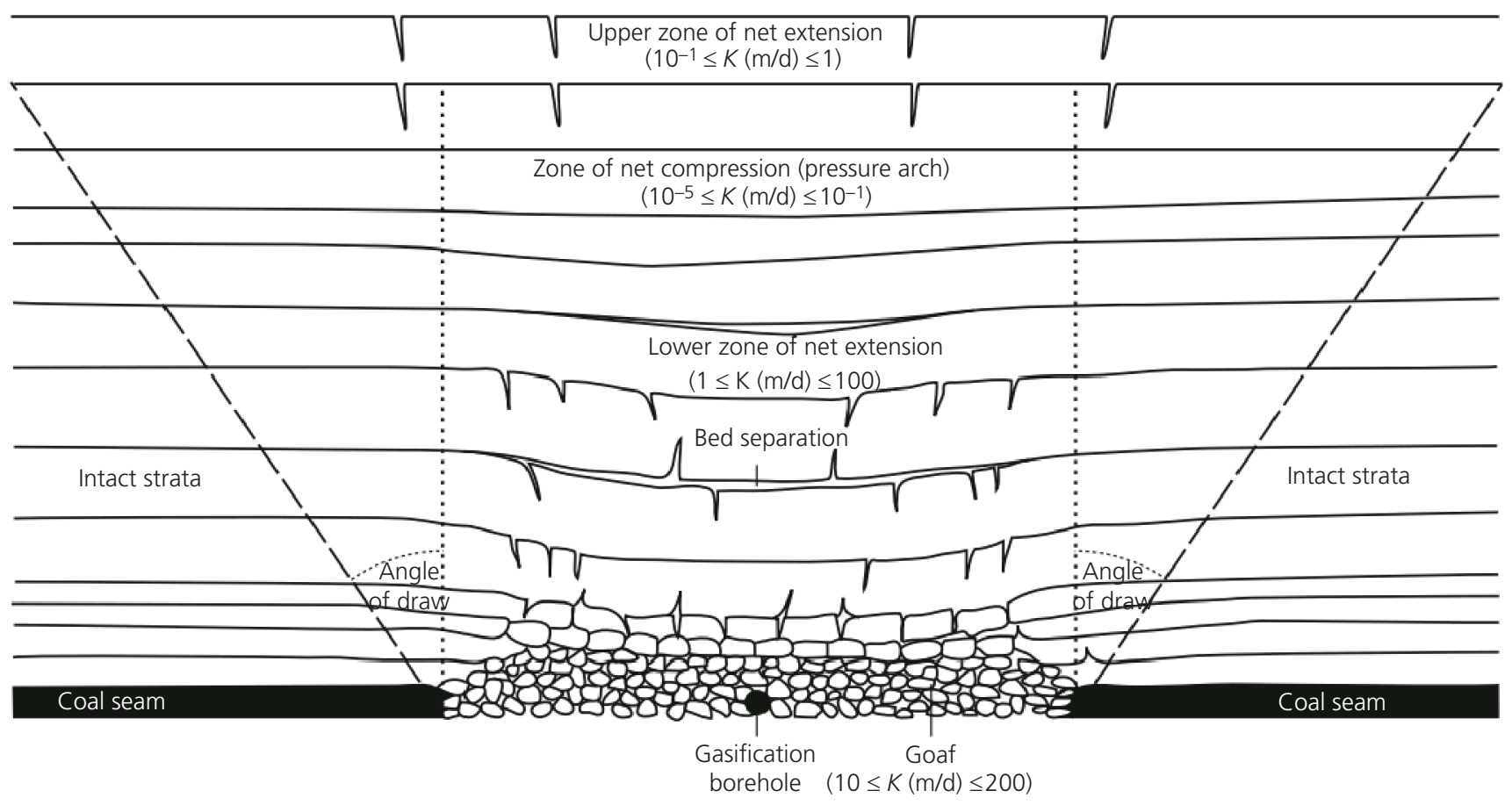

Figure 4. Schematic diagram of a cross-section showing the impacts of void collapse around a gasification borehole, forming goaf (rubble filling the former void) and overlying zones of extensional and compressional deformation (Younger, 2011). The values of $K$ (hydraulic conductivity in metres per day) are approximate values derived from a range of literature sources compiled by Younger and Adams (1999)
In order to further control the subsidence of a commercial UCG development, coal pillars are left between two adjacent L-CRIP modules, as is the case for coal mining. The width of the pillar compared with the maximum cavity width is determined prior to designing the UCG drilling panel and should be based on the geomechanical properties of the overburden.

\section{Site selection}

One of the most important elements of risk management is site selection (Mastalerz, 2011; Sheng et al., 2015). Although a number of quantitative and semi-quantitative site selection criteria have been published (e.g. Mastalerz et al., 2011; Oliver and Dana, 1991), it is now generally accepted that UCG should take place in deep coal seams (typically $>300 \mathrm{~m}$ ) and overlain by rock with high mechanical strength, low permeability and minimal faulting (Sheng et al., 2015). The target coal seam and surrounding rocks should be saturated with water and not be located near any groundwater resources (DECC, 2012).

In addition to minimising environmental risks, site selection plays a key role in ensuring that a commercial UCG project is profitable (Nakaten et al., 2014a). Ignoring the effects of gasification efficiency and coal quality, the greater the volume of coal converted per module, the more economic the project is. The volume of coal converted per module depends on the coal seam thickness, the inseam length (i.e. the distance between injection and production wells) and the volume of the on-site reactor. While coal seam thickness is clearly an intrinsic property of a coal seam that cannot be changed, the other two factors are limited by site conditions and must be optimised in order to maximise the project's profitability (Nakaten et al., 2014b).

Coal quality (i.e. the energy density of the coal) also plays a fundamental role in ensuring a profitable UCG project. The higher the calorific value of a coal, the more energy that can be recovered per module and the better the project's economics (Nakaten et al., 2014b).

Depending on the depth of UCG (i.e. from 300 to $1500 \mathrm{~m}$ deep), fully optimised UCG modules could be expected to produce raw syngas at a rate equivalent to $30-150 \mathrm{MW}_{\text {thermal }}$. Such power outputs are probably too small to support a commercial UCG project, so multiple modules will have to be operated simultaneously. The UCG industry has a limited experience of operating multiple UCG modules simultaneously, and it is recognised that future commercial projects would require time to demonstrate to investors, regulators and the public that economic and financial risks from the technology can be managed. 
Operating in the natural environment is one of the key aspects that have to be worked on. It will therefore be necessary to grow projects progressively, from the initial one or two modules ('earlycommercial') to perhaps six to seven ('semi-commercial') to ten or more modules ('full-commercial') operating simultaneously. Eventually, this will be able to provide confidence and long-term commercial guarantees for the environmental impact, gas quality and specification. The UCG industry could potentially take a similar path to full resource development as the one that took place in the coal bed methane (CBM) industry in the USA (IPCC, 2001), with the aid to full commercial development in many coalproducing countries in Europe and around the globe.

\section{Enabling technologies}

Technical advancements in directional drilling, seismic surveying, high-temperature- and acid gas-resistant well engineering and onsite controlling and monitoring techniques have been key to pushing UCG beyond the proof-of-concept phase. Directional drilling is a technique that allows boreholes to be drilled at various angles, with trajectories controlled such that a borehole can be made to intersect another over a kilometre away. Modern drilling technologies (e.g. measurement-while-drilling and downhole motor technologies) have been used by the oil and gas industry for decades and have allowed more recently the CBM and shale gas industries to commercialise. The now routine use of directional drilling in these industries has greatly reduced its cost, making it an affordable 'off-the-peg' technology for UCG.

Recent developments in seismic source generation (e.g. seismic vibration technology and improvements in seismic processing from the oil and gas industry) have now made it possible to produce accurate, high-resolution maps of coal seams to depths of around $2 \mathrm{~km}$. Knowing how the coal seam changes improves the accuracy of directional drilling by allowing the driller to anticipate changes and maintain the borehole in the correct position at the base of the coal seam.

Previous trials demonstrated that the chemical and physical conditions encountered during UCG could be detrimental to the conventional borehole completion materials used by the oil and gas industry. Advancements in borehole material manufacture (e.g. stainless, nickel and duplex-steel alloys) have made it possible to construct UCG modules from modern corrosion-resistant materials and precision-manufactured components, improving their longevity and integrity under the challenging conditions of UCG.

Careful, real-time controlling and monitoring of UCG is essential to maximise efficiency while minimising environmental risks. Until relatively recently, there were few options available to control and monitor the conditions in real time. New down-hole controlling and monitoring technologies, such as optical time domain reflectometry and distributed temperature measurement by way of fibre-optic cables, developed by the oil and gas industry, allow direct measurement of UCG reactor conditions, enabling the operator to carefully control UCG in real time. Other technologies allow the UCG reactor to be monitored from the surface, such as microgravimetric and microseismic methods, while gas tracer tests and mass balance calculations allow the volume of the reactor to be predicted, as well as the detection of gas leakage.

\section{Summary of UCG activities in the EU}

Previous trials

Europe has a long history of undertaking UCG trials, beginning with the trials at Bois-la-Dame, Belgium, in 1948, the trials at Newman Spinney, UK (1949-1959), to the trials in Polish coal mines in 2014. These trials were undertaken at shallow depths $(<100 \mathrm{~m})$; the most significant trials for the commercialisation of UCG were undertaken at greater depths. The first of these was the EU-funded Belgo-German UCG experiment in Thulin, Belgium, during the late 1980s, which was the first to be undertaken at a depth of over $800 \mathrm{~m}$. The Thulin project initially used LVW techniques and demonstrated that more advanced techniques (i.e. directional drilling) were required to gasify deep, low-permeability coals. The project subsequently used short-radius directional drilling and well completion materials adopted from the oil and gas industry to create the first ever deep L-CRIP module.

The second major phase of development was an EU-funded trial between Spain, Belgium and the UK during 1991-1997. The UCG trial at El Tremedal, Teruel Province, Spain, demonstrated the technical feasibility of carrying out UCG at a depth of $600 \mathrm{~m}$ by using the L-CRIP technology. The effectiveness of L-CRIP at gasifying deep coal has since been further validated by a trial at $1400 \mathrm{~m}$ depth in Alberta, Canada.

\section{Summary of current EU-funded research studies}

Following the UCG trials, the EU-based Research Fund for Coal and Steel has provided significant funding to support further research in the UCG. The first of these were the Hydrogen Oriented Underground Coal Gasification for Europe projects (HUGE, 2007-2010, and HUGE2, 2011-2014), which were coordinated by the Central Mining Institute in Poland (Li et al., 2007). The second was known as the UCG \& $\mathrm{CO}_{2}$ Storage project (2010-2012), and currently the Coal2Gas project (2014-2017) is investigating UCG in Romania. Several EU-based universities currently carry out research into UCG modelling (e.g. Yang et al., 2014) and carbon dioxide storage (e.g. Sarhosis et al., 2013; Sheng et al., 2015) and undertake laboratory-based experiments (e.g. Kempka et al., 2011; Konstantinou and Marsh, 2015; Stanczyk et al., 2011). Collaboration and sharing between these and other projects has been key to the development and growth of the UCG industry.

\section{Commercialising UCG: overcoming barriers at the European level}

\section{Regulatory hurdles and political issues}

Although UCG is ready for commercialisation, the technology remains new to the public and to regulators. Licensing policies are present in some countries (e.g. Australia, UK, Canada, New Zealand, the USA), but the general lack of specific regulations, or 
knowledge of how to apply existing regulation, has restricted field trials and commercial development in many EU countries.

Government support of UCG field trials is needed to grow the knowledge base, gain more environmental data and attract more private investment. Although it is recognised that investors have confidence in the long-term future of the UCG as an option for low-carbon dioxide electricity production (e.g. Nakaten et al., 2014a; Walker, 2014), the technology needs to 'de-risked' from both economic and environmental perspectives in the near to medium term. This can be achieved by permitting field trials using modern approaches and state-of-the-art equipment, carefully monitored and regulated, to demonstrate that UCG can exploit the energy in coal resources with limited environmental impact compared with conventional technologies. Additionally, some commercial field projects could serve to test the possibility of storing carbon dioxide in the spent reactors (and overburden) and evaluate other technologies, such as microbial production of methane from coal and/or methane production from the overburden.

\section{Public perception}

Before a field trial can be undertaken, it will be essential to gain approval from the local population as well as regulators and the local government; a key obstacle to UCG commercialisation is adverse public perception. Understanding public attitudes and the ways in which energy and technologies are themselves understood and used is vital for a technology to progress to commercialisation (e.g. Whitmarsh et al., 2011). A study carried out by Shackley et al. (2006) indicated that an open, transparent and consultative process of decision-making and operation should be adopted by the developer, operator and regulator. Also, the trial should be sited carefully, preferably in land with a history of industry (e.g. coal mining), and it should be made clear that UCG will never be undertaken in populated areas or environmentally sensitive areas.

\section{Reducing greenhouse gas emissions}

UCG, like all fossil fuel-based energy technologies, produces carbon dioxide. Carbon dioxide emissions will remain an important factor for UCG in the twenty-first century as the EU continues to reduce greenhouse gas emissions; UCG projects will have to limit carbon dioxide emissions to gain approval and not incur large financial penalties. The UCG industry is currently adapting to this by investigating the potential for combined UCG and carbon dioxide capture and sequestration/utilisation ( $\mathrm{CCS} / \mathrm{U})$, as well as the re-use of carbon dioxide by way of processes such as enhanced oil recovery.

As UCG syngas is similar to other gases produced by the industries, the technologies for capturing carbon dioxide from UCG syngas are in existence, well understood and widely available. Relatively little adaption of these technologies to UCG syngas will be required. The principal barrier to combined UCG-CCS is sequestration. Efforts continue around the EU to develop sequestration sites, but the progress is slow, and this, above all others, is probably the most difficult obstacle to overcome for UCG to commercialise in the EU.
Although not a 'magic bullet', UCG does offer some advantages compared with conventional technologies regarding CCS. UCG produces syngas relatively inexpensively and is undertaken close to potential sequestration sites (such as deep saline aquifers or depleted gas reservoirs), limiting the cost impact of capture and sequestration. It may also be possible to inject carbon dioxide into the spent UCG reactors, but this is currently hypothetical and has never been tested. As with other fossil-fuel technologies, the future of UCG is intimately associated with the commercial development of CCS/U.

\section{Conclusions}

Although the idea of UCG dates back about 100 years, it has never been fully commercialised. Lessons learned from previous trials, together with advancements in key enabling technologies, have recently pushed UCG beyond the proof-of-concept phase, readying UCG for full commercialisation. Application of modern UCG techniques, state-of-the-art drilling and completion and monitoring technologies offer the opportunity to extract the energy from deep coal resources economically and with limited environmental impact. This, combined with factors such as energy security, has recently caused renewed interest in UCG in the EU, particularly in those countries with large but unmineable coal resources and limited oil and gas reserves.

There are several hurdles, such as public perception and regulatory issues, which must be overcome before UCG can commercialise. The most significant hurdle is to reduce carbon dioxide emissions, a common factor to all fossil fuel-based energy technologies. Although not a magic bullet, UCG offers several advantages over conventional coal technologies as it does not require mining or coal processing and transportation, but progress in CCS must be made before UCG can realise its full potential in the EU.

The EU has a long history of supporting UCG research and has funded some of the most significant UCG trials undertaken to date. Collaboration and sharing expertise and knowledge between projects and governments with experience in UCG has been key to the development of the UCG industry. Continued support by member states is required to attract private investment, enable more field trials and allow Europe's world-class experts to demonstrate that UCG is ready to provide clean energy for the EU in the twenty-first century.

\section{REFERENCES}

Bhutto AW, Bazmi AA and Zahedi G (2013) Underground coal gasification: from fundamentals to applications. Progress in Energy and Combustion Science 39(1): 189-214, http://dx.doi. org/10.1016/j.pecs.2012.09.004.

Blindermann MS, Saulovb DN and Klimenko AY (2008) Forward and reverse combustion linking in underground coal gasification. Energy 33(1): 446-454, http://dx.doi.org/10.1016/ j.energy.2007.10.004.

Boysen JE, Covell JR and Sullivan S (1990) Rocky Mountain 1 Underground Coal Gasification Test, Hanna, WY - Results from Venting, Flushing, and Cooling of the Rocky Mountain 1 
UCG Cavities. Gas Research Institute, Chicago, IL, USA, GRI Publication No. 90/0156.

BP (2015) BP Energy Outlook 2035: Country and Regional Insights - EU. BP, London, UK.

Burton E, Friedmann J and Upadhye R (2006) Best Practices in $U C G$. Lawrence Livermore National Laboratory, Livermore, CA, USA.

Cena RJ, Britten JA and Thorness CB (1988) Resource recovery and cavity growth during the Rocky Mountain I field test. 14th UCG Annual Symposium, Chicago, IL, USA.

Couch G (2009) Underground Coal Gasification. International Energy Agency Clean Coal Centre, London, UK, Report No. CCC $/ 151$.

Creedy DP, Garner K, Holloway S et al. (2001) Review of underground coal gasification technological advancements. UK DTI Cleaner Coal Technology Transfer Program, London, UK.

DECC (Department of Energy and Climate Change) (2012) The Unconventional Hydrocarbon Resources of Britain's Onshore Basins - Coal Bed Methane CBM. DECC, London, UK, Promote UK Report 2013.

DTI (Department of Trade and Industry) (2004) Review of Environmental Issues of Underground Coal Gasification. DTI, London, UK, Report No. COAL R272 DTI/Pub URN 04/1880.

Euracoal (2013) The European Association for Coal and Lignite. Euracoal, Brussels, Belgium. See http://euracoal.eu/ (accessed 10/10/2015).

Friedmann SJ, Upadgye R and Kong FM (2009) Prospects for underground coal gasification in carbon-constrained world. Energy Procedia 1(1): 4551-4557, http://dx.doi.org/10.1016/j. egypro.2009.02.274.

IEA (International Energy Agency) (2014) Medium-Term Coal Market Report 2014: Market Analysis and Forecasts to 2019. IEA, Paris, France.

IPCC (Intergovernmental Panel on Climate Change) (2001) Climate Change 2001: Working Group III, Mitigation Climate Change. IPCC, Geneva, Switzerland.

Kempka T, Fernandez-Steeger T, Li D et al. (2011) Carbon dioxide sorption capacities of coal gasification residues. Environmental Science and Technology 45(4): 1719-1723, http://dx.doi.org/10.1021/es102839x.

Konstantinou E and Marsh R (2015) Experimental study on the impact of reactant gas pressure in the conversion of coal char to combustible gas products in the context of Underground Coal Gasification. Fuel 159: 508-518, http://dx.doi.org/10. 1016/j.fuel.2015.06.097.

Li Y, Liang X and Liang J (2007) An overview of the Chinese UCG program. Data Science Journal 6(1): 460-466.

Mastalerz M, Drobniak A, Parke M et al. (2011) Site Evaluation of Subsidence Risk, Hydrology, and Characterization of Indiana Coals for Underground Coal Gasification. Centre for Coal Technology Research (CCTR) Energy Centre, Purdue University, West Lafayette, IN, USA, Indiana Geological Survey final report for the CCTR.

Nakaten N, Schlüter R, Azzam R et al. (2014a) Development of a techno-economic model for dynamic calculation of cost of electricity, energy demand and $\mathrm{CO}_{2}$ emissions of an integrated UCG-CCS process. Energy 66: 779-790, http://dx.doi.org/10. 1016/j.energy.2014.01.014.

Nakaten N, Azzam R and Kempka T (2014b) Sensitivity analysis on UCG-CCS economics. International Journal of Greenhouse Gas Control 26: 51-60, http://dx.doi.org/10.1016/ j.ijggc.2014.04.005.

Oliver RL and Dana GFP (1991) Underground coal gasification. In Geology in Coal Resource Utilisation (Peters DC (ed.)). TechBooks, Falls Church, VA, USA, pp. 155-168.

Osborne D (2013) The Coal Handbook: Towards Cleaner Production. Woodhead Publishing, New York, NY, USA.

Roddy DJ and Younger PL (2010) Underground coal gasification with CCS: a pathway to decarbonising industry. Energy \& Environmental Science 3(1): 400-407, http://dx.doi.org/10. 1039/B921197G.

Sarhosis V, Yang D, Sheng Y and Kempka T (2013) Coupled hydro-thermal analysis of Underground Coal Gasification rector cool down for subsequent $\mathrm{CO}_{2}$ storage. Energy Procedia 40(1): 428-436, http://dx.doi.org/10.1016/j.egypro.2013.08.049.

Shackley S, Mander S and Reiche A (2006) Public perceptions of underground coal gasification in the United Kingdom. Energy Policy 34(18): 3423-3433, http://dx.doi.org/10.1016/j.enpol. 2005.07.010.

Sheng Y, Benderev A, Bukolska D et al. (2015) Interdisciplinary studies on the technical and economic feasibility of deep underground coal gasification with $\mathrm{CO}_{2}$ storage in Bulgaria. Mitigation and Adaptation Strategies for Global Change, http://dx.doi.org/10.1007/s11027-014-9592-1.

Stanczyk K, Howaniec N, Smolinski A et al. (2011) Gasification of lignite and hard coal with air and oxygen-enriched air in a pilot scale ex-situ reactor for underground gasification. Fuel 90(5): 1953-1962, http://dx.doi.org/10.1016/j.fuel.2010.12.007.

Sury M, White M, Kirton J et al. (2004) Review of Environmental Issues of Underground Coal Gasification. WS Atkins Consultants Ltd., University of Liège Belgium, FWS Consultants Ltd., 126. Report No. COAL R272 DTI/Pub URN 04/1880, pp. 1-126.

Swan Hills Synfuels (2012) Swan Hills Coal Gasification Technology Development: Final Outcomes Report. Alberta Innovates - Energy and Environment Solutions, Calgary, AB, Canada.

UCGP (Underground Coal Gasification Partnership) (2007) Briefing Note on Underground Coal Gasification. UCGP, London, UK.

Walker L (2014) Underground coal gasification: issues in commercialisation. Proceedings of the Institution of Civil Engineers - Energy 167(4): 188-195, http://dx.doi.org/10. 1680/ener.14.00003.

Whitmarsh L, Upham P, Poortinga W et al. (2011) Public Attitudes to Low-Carbon Energy - Research Synthesis. Research Councils UK, London, UK.

Yang D, Sarhosis V and Sheng Y (2014) Thermo-mechanical modelling around the UCG reactor. Journal of Energy Institute 87(4): 321-327, http://dx.doi.org/10.1016/j.joei.2014.03.029. 
Younger PL (2011) Hydrogeological and geomechanical aspects of underground coal gasification and its direct coupling to carbon capture and storage. Mine Water and the Environment 30(2): 127-140, http://dx.doi.org/10.1007/ s10230-011-0145-5.
Younger PL and Adams R (1999) Improved Modelling of Abandoned Coalfields: Fifth Six-Monthly Progress Report to the Environment Agency and Northumbrian Water Ltd IEA R\&D Contract No B04(95)2. Department of Civil Engineering, University of Newcastle, Newcastle upon Tyne, UK.

\section{WHAT DO YOU THINK?}

To discuss this paper, please submit up to 500 words to the editor at journals@ice.org.uk. Your contribution will be forwarded to the author(s) for a reply and, if considered appropriate by the editorial panel, will be published as a discussion in a future issue of the journal. 